\title{
Thermosensitive Progesterone Hydrogel: A Safe and Effective New Formulation for Vaginal Application
}

Aliyah Almomen • Sungpil Cho • Chieh-Hsiang Yang • Zhengzheng Li • Elke A. Jarboe • C. Matthew Peterson • Kang Moo Huh • Margit M. Janát-Amsbury

Received: 8 October 2014 / Accepted: 26 December 2014 / Published online: 22 January 2015

(C) The Author(s) 2015. This article is published with open access at SpringerLink.com

\begin{abstract}
Purpose The safe and functional delivery of progesterone through the vaginal route remains an unmet clinical need. The purpose of this work is to prepare a new progesterone (P4) gel for vaginal application using a thermosensitive mucoadhesive polymer, glycol chitin (GC).

Method Thermogelling, mucoadhesive, mechanical, and viscoelastic properties of GC and the new formulation were evaluated using rheometry. In vitro release profile and the bioactivity of P4 were determined using vaginal fluid simulant (VFS) $\mathrm{pH}$ 4.2, and PRreporter gene assay, respectively. In vitro safety of the formulations was tested using (VK2/E6E7) vaginal epithelial cell line and Lactobacillus Crispatus. Finally, in vivo safety and the efficacy of this formulation were evaluated using an endometrial hypoplasia mouse model.
\end{abstract}

Results Results shows the aqueous solution of 5\%; (w/v) GC loaded with 0.1\%; (w/V) P4 prepared in pH 4.2, (GC-P4), forms a thermosensitive mucoadhesive hydrogel and can maintain stable physical properties at $37^{\circ} \mathrm{C}$. GC-P4 gel release $50 \%$ of P4 in $4 \mathrm{~h}$ after exposure to VFS, and no significant decrease in \% viability of VK2/E6E7 or Lactobacillus was found after exposure to $5 \%$ GC or GC-P4. GC-P4 does not exhibit obvious toxicities to vaginal tissue in vivo even after repeated application. Efficacy studies indicated that GC-P4 was capable of preventing the progression of simple endometrial hyperplasia (SEH) to complex atypical endometrial hyperplasia (CAEH) in vivo.

Conclusions Results indicates that GC-P4 retains many characteristics for an effective vaginal delivery system for P4. Therefore we believe that GC-P4 formulation is a promising alternative to current vaginal P4 formulation.

KEY WORDS glycol chitin · mucoadhesive · progesterone . thermosensitive $\cdot$ vaginal gel

\section{ABBREVIATIONS}

CAEH Complex atypical endometrial hyperplasia

CFU Colony forming unit

COS Critical oscillatory stress

DA Degree of acetylation

E2 Estrogen

EH Endometrial hyperplasia

$G^{\prime} \quad$ Elastic modulus

G" Viscous modulus

Electronic supplementary material The online version of this article (doi: | 0. I007/s | | 095-0 |4-|6 |6-8) contains supplementary material, which is available to authorized users.

A. Almomen · S. Cho $\cdot$ C.-H. Yang $\cdot$ E. A. Jarboe $\cdot$ C. M. Peterson $\cdot$ M. M. Janát-Amsbury $(\square)$

Department of Obstetrics and Gynecology, Division of Gynecologic Oncology, University of Utah, Salt Lake City, Utah 84I32, USA

e-mail: margit.janat-amsbury@hsc.utah.edu

A. Almomen • M. M. Janát-Amsbury

Department of Pharmaceutics and Pharmaceutical Chemistry

University of Utah, Salt Lake City, Utah 84I I2, USA

C.-H. Yang • M. M. Janát-Amsbury

Department of Bioengineering University of Utah

Salt Lake City, Utah 84I I2, USA
E. A. Jarboe

Department of Pathology University of Utah

Salt Lake City, Utah 84I I2, USA

K. M. Huh $(\varangle)$

Department of Polymer Science and Engineering Chungnam National University, 220 Gung-dong, Yuseong-gu, Daejeon

305-764, Republic of Korea

e-mail:khuh@cnu.ac.kr

Z. Li

School of Materials Science and Chemical Engineering Tianjin University of Science \& Technology Tianjin 300457, China 


$\begin{array}{ll}\text { GC } & \text { Glycol chitin } \\ \text { GC-P4 } & 5 \% \text { glycol chitin- } 0.1 \% \text { progesterone at } \mathrm{pH} 4.2 \\ \text { H\&E } & \text { Hematoxylin and Eosin staining } \\ \text { HRT } & \text { Hormonal replacement therapy } \\ \text { IM } & \text { Intramuscular } \\ \text { LVR } & \text { Linear viscoelastic region } \\ \text { OD } & \text { Optical density } \\ \text { P4 } & \text { Progesterone } \\ \text { S.C. } & \text { Subcutaneous } \\ \text { SEH } & \text { Simple endometrial hyperplasia } \\ \text { SFS } & \text { Seminal fluid simulant } \\ \text { Tgel }_{\text {gel }} & \text { Gelation temperature } \\ \text { VFS } & \text { Vaginal fluid simulant } \\ \Delta G & \text { Absolute synergism parameter }\end{array}$

\section{Introduction}

Progesterone (P4) is a female steroidal hormone that plays a crucial role in maintaining normal physiology of the female reproductive system. P4 is mainly involved in benign, cycledependent tissue proliferation of the uterus, ovulation, implantation of the fertilized ovum, and maintenance of pregnancy (1). Other physiological actions of $\mathrm{P} 4$ include the proliferation of normal breast tissue, protection against bone loss, as well as regulation of sexual responsive signals in the brain (1). Based on its broad impact, the therapeutic use of $\mathrm{P} 4$ has been applied in the management of various female reproductive conditions such as the prevention of preterm birth, luteal phase support, and in hormonal replacement therapy (HRT) $(2-4)$. Furthermore, the antiestrogenic effect of $\mathrm{P} 4$ on the endometrium led to the emergence of $\mathrm{P} 4$ therapy as a part of fertility-sparing treatment for endometrial hyperplasia $(\mathrm{EH})$ and primary endometrial carcinoma (EC) (5).

Various different options of $\mathrm{P} 4$ administration and formulation are available. Oral administration of bio-identical P4 provides convenient dosing. However, poor bioavailability due to the hepatic first pass effect provides only low endometrial P4 concentrations (6). On the other hand, synthetic P4 known as progestins, are commonly associated with undesirable side effects ranging from acne and water retention to depression (7). To better facilitate the cellular absorption, intramuscular (IM) injections of $\mathrm{P} 4$ have become a popular administration route. Yet, pain with injection, irritation at the injection site, infections and possible abscesses leading to neuropathies in some cases, can reduce patient compliance, and therefore therapeutic efficacy (8). In light of the aforementioned limitations, the vaginal route has gained acceptance as a viable drug delivery route, especially in the management of obstetrical and gynecological conditions $(9,10)$. In addition, the vaginal administration of $\mathrm{P} 4$ exhibits a preferential absorption and distribution to the uterus based on the uterine first pass effect, a direct transport mechanism for drugs from vagina to the uterus $(11,12)$.

Although vaginal $\mathrm{P} 4$ formulations such as suppositories and creams show clear advantages over other routes including the avoidance of the hepatic first pass effect, ease of administration, and the provision of site-specific treatments, currently available $\mathrm{P} 4$ vaginal formulations exhibit major drawbacks (6). The challenging vaginal environment including body temperature $\left(37^{\circ} \mathrm{C}\right)$, a more acidic $\mathrm{pH}(4.5-5.5)$, vaginal secretions, and the self-cleansing mechanisms lead to the leakage of almost all formulations resulting in significantly decreased vaginal residence times, local tissue irritation and inflammation, more frequent yeast infections, and most importantly the loss of active ingredients responsible for an unsatisfactory therapeutic effect $(2,13)$.

Recently, thermosensitive polymers possessing a reversible sol-gel transition behavior in aqueous media have been utilized for vaginal delivery of various drugs such as 5fluorouracil and metronidazole $(9,10)$. Such gels were found to provide a convenient and effective treatment method, especially if combined with mucoadhesive agents (9). In a previous report, we introduced glycol chitin $(\mathrm{GC})$, which has proven to be a suitable candidate for various biomedical applications including its use as an injectable drug delivery vehicle and a potential new material for tissue engineering purposes (14). In addition, chitosan amphiphilic derivatives are known to enhance the solubility of hydrophobic agents $(15,16)$.

Based on the aforementioned characteristics, we report for the first time the application of GC in vaginal drug delivery and it usage as a carrier for P4. We hypothesized that GG-P4 provide a safe, effective, and a better alternative to currently available vaginal $\mathrm{P} 4$ formulations. In order to confirm our hypothesis, several rheological, release profiles, as well as in vitro and in vivo safety and efficacy studies of the hydrogel system were conducted.

\section{Materials and Methods}

\section{Materials}

Progesterone was purchased from Spectrum (Gardena, CA, USA). Glycol chitosan (DP $\geq 400)$, acetic anhydride (99.5\%), and Porcine stomach derived Mucin type III were purchased from Sigma-Aldrich (St. Louis, MO, USA). Crinone ${ }^{\circledR}$ gel was purchased from Watson Pharmaceutics (Morristown, NJ, USA). Gynol II® was purchased from Revive (Madison, NJ, USA). All other chemical reagents used were of analytical grade and used without further purification. 


\section{Cell Culture}

VK2/E6E7, Human vaginal epitheliums cell line (CRL-2616) and 293 T human embryonic kidney cells line (CRL-3216) were purchased from the American Type Cell Culture collection (ATCG, Manassas, VA). VK2/E6E7 were cultured in Keratinocyte-Serum Free medium (Invitrogen, Grand Island, NY, USA), supplemented with $0.1 \mathrm{ng} / \mathrm{ml}$ human recombinant epidermal growth factor, $0.05 \mathrm{mg} / \mathrm{ml}$ bovine pituitary extract, 100 units $/ \mathrm{ml}$ penicillin, $100 \mu \mathrm{g} / \mathrm{ml}$ streptomycin, and additional calcium chloride of $0.4 \mathrm{mM}$. $293 \mathrm{~T}$ were cultured in Dulbecco's Modified Eagle's Medium (DMEM) supplemented with $10 \%$ fetal bovine serum (FBS), 100 units/ $\mathrm{ml}$ penicillin, and $100 \mu \mathrm{g} / \mathrm{ml}$ streptomycin. Cells were grown and routinely maintained at $37^{\circ} \mathrm{C}$ in $10-\mathrm{cm}^{2}$ culture dishes. Lactobacillus crsipatus was purchased from ATCG and grown in an ATCG medium 146 Lactobacillus MRS agar/broth (BD, Sparks, $\mathrm{MD}, \mathrm{USA})$ at $37^{\circ} \mathrm{C}$.

\section{Animal Studies}

Female $\mathrm{Nu} / \mathrm{Nu}$ mice $(6-8$ week old) were obtained from Jackson Laboratory (Bar Harbor, ME USA). Mice were housed at the Center for Comparative Medicine Animal Facility and treated following approved Institutional Animal Care and Use Committee (IACUC) protocols and guidelines.

\section{Glycol Chitin (GC) Hydrogel for Vaginal Application}

\section{Preparation of Glycol Chitin (GC)}

GC with $\approx 90 \%$ degree of acetylation (DA) was chosen in this study and was synthesized and characterized as described previously (14). The synthetic method and results are described on Supporting Information and (Fig S1). GC solution was prepared according to the modified cold method (17). Briefly, GG was slowly added to cold citrate phosphate buffer $\left(4^{\circ} \mathrm{C}, 0.1 \mathrm{M}, \mathrm{pH}\right.$ 4.2) under gentle mixing and allowed to dissolve completely for $24 \mathrm{~h}$ at $4^{\circ} \mathrm{C}$.

\section{Effect of Concentration and pH on GC Gelation}

To test the effect of concentration and $\mathrm{pH}$ on GC gelation temperature $\left(\mathrm{T}_{\mathrm{gel}}\right), \mathrm{GC}$ solutions were prepared at various concentrations of 5,6 , and $7 \%$; $(\mathrm{w} / \mathrm{v})$ at $\mathrm{pH} 4.2 . \mathrm{T}_{\text {gel }}$ were determined by using a stress-controlled rheometer (AR 550; TA instrument, DE, USA). The rheometer was equipped with $20 \mathrm{~mm} 4^{\circ}$ steel cone geometry. Frequency and oscillatory stress were maintained with constant values of $1 \mathrm{~Hz}$ and $5 \mathrm{~Pa}$, respectively. The temperature sweep analyses were conducted in the range of $15-45^{\circ} \mathrm{C}$ with a heating rate of $1^{\circ} \mathrm{C} / \mathrm{min}$. The gelation point was considered to be at the crossover point between $G^{\prime}$ (elastic modulus) and $G^{\prime \prime}$ (viscous modulus). Effect of $\mathrm{pH}$ on gelation was measured on the GC's concentration showing a $\mathrm{T}_{\text {gel }}$ within the acceptable temperature range for mucosal application between $\left(30-36^{\circ} \mathrm{C}\right)$ at $\mathrm{pHs}$ of $4.2,6$ or $7.2(10)$.

\section{Rheological Examination of GC Mucoadhesive Characteristic}

To determine mucoadhesive property of GC, a GG-mucin mixture was prepared at $\mathrm{pH}$ 4.2. The final concentrations of mucin and GC in the solutions were 4 and $5 \%$; (w/v) respectively (18). GC and mucin were mixed prior to rheological evaluation. The linear viscoelastic region (LVR) for each sample was determined through a strain sweep measurement at a constant frequency of $1 \mathrm{~Hz}$ and $37^{\circ} \mathrm{C}$. Frequency sweep analysis was performed at a range of $0.1-10 \mathrm{~Hz}$ within the LVR of the gel (19). Mean $G^{\prime}$ for samples were extracted from frequency sweep spectra. Positive values of the absolute synergism parameter $(\Delta G)$, which is a equal to the interaction between polymer and mucin, is an indicative of mucoadhesion (20). The following equation was used to calculate $\Delta G(20)$ :

$\Delta G=G_{m i x}^{\prime}-G_{p}^{\prime}$

Where $G_{\text {mix }}^{\prime}$ and $G_{p}^{\prime}$ are the elastic moduli for polymer-mucin mixture and the polymer alone, respectively. The contribution of the mucin elastic modulus $\left(G_{m}^{\prime}\right)$ was neglected in the equation since it was relatively low.

\section{Glycol Chitin-Progesterone (GC-P4) Hydrogel}

\section{Solubility of P4 in GC Solutions}

To test the solubility of $\mathrm{P} 4$ in GC, $\mathrm{P} 4$ was mixed in GC solutions $(1-5 \% ; \mathrm{w} / \mathrm{v})$ and stirred for $24 \mathrm{~h}$ at $4^{\circ} \mathrm{C}$. The clear GC-P4 solution collected from centrifugation (12, $000 \mathrm{RPM}, 4^{\circ} \mathrm{C}$ ) was used to determine the amount of solubilized P4 employing reversed phase (RP)-HPLG (Agilent Chemstation for LC/MS system, CA, USA) equipped with a C18 column at $254 \mathrm{~nm}$ (21). A mixture of methanol/water $(80: 20 ; \mathrm{v} / \mathrm{v})$ was used, as the mobile phase at a flow rate of $1 \mathrm{ml} / \mathrm{min}$. 


\section{Preparation of GC-P4 Hydrogel}

GC-P4 gel was prepared by adding $\mathrm{P} 4$ into the $5 \%$ GC solution ( $\mathrm{pH} 4.2)$ in a concentration that exceeded it solubility and stirred for $24 \mathrm{~h}$ at $4^{\circ} \mathrm{C}$. The final $\mathrm{P} 4$ concentration in GC solution was of $0.1 \%$; (w/v). Osmolarity of GC-P4 was 358.16 $\pm 6.5 \mathrm{mmol} / \mathrm{kg}$. $\mathrm{T}_{\text {gel }}$ for GC-P4 hydrogel was assessed using the same method described earlier.

\section{Mechanical Characteristics of GC-P4 Hydrogel}

\section{Dynamic Oscillatory Rheology}

To determine the mechanical spectra of GC-P4 hydrogel, an oscillatory stress sweep step was conducted using a stressedcontrolled rheometer equipped with $20 \mathrm{~mm} 4^{\circ}$ steel cone geometry. One hundred and fifty microliter of GC-P4 was placed on the Palter plate. The sample was allowed to equilibrate for $5 \mathrm{~min}$ at room temperature $25^{\circ} \mathrm{C}$ as well as $37^{\circ} \mathrm{C}$. An oscillatory stress step was conducted in the ranges of $0.5-$ $1000 \mathrm{~Pa}$ at a frequency of $1 \mathrm{~Hz}$. The critical oscillatory stress (COS), the maximum stress at which the linear value of $G^{\prime}$ is disturbed, was obtained from the stress step spectra (22). Mechanical spectra of Crinone ${ }^{\circledR}$ and GC-P4 were also determined to compare the strengths of the two gels in vaginal like environment. The value of stress representative of the viscoelastic region of GC-P4 was used in the oscillatory frequency analysis $(5 \mathrm{~Pa})$. Oscillatory frequency step was conducted in a frequency range of $0.1-10 \mathrm{~Hz}$ at 25 and $37^{\circ} \mathrm{C}(19,23)$.

\section{Steady Shear Viscosity (Flow rheology)}

To determine flow behavior of GG-P4, a shear step was conducted in the biological relevant shear of $0.1-100 \mathrm{~s}^{-1}$, resembling shear exposed by passive seeping of vaginal epithelium all the way to shear during coitus, respectively (23-25). Frequency was kept constant at $1 \mathrm{~Hz}$. The sample was allowed to equilibrate for $5 \mathrm{~min}$ at 25 and $37^{\circ} \mathrm{C}$ prior initiation of the shear step.

\section{Rate of GC-P4 Gelation}

To determine the time required for GC-P4 to transform to a gel state at body temperature, a time sweep analysis was conducted. Time sweep analysis was set for $10 \mathrm{~min}$ at a constant frequency of $1 \mathrm{~Hz}$ in addition of $5 \mathrm{~Pa}$ oscillatory stress. The sample was set to equilibrate for $5 \mathrm{~min}$ at $15^{\circ} \mathrm{C}$ in the conditioning step to assure the liquid state of GC-P4 before initiating the time sweep. At the onset of time sweep, the temperature was raised to $37^{\circ} \mathrm{C}$ and gelation time was recorded.

\section{GC-P4 Hydrogel in Biologically Relevant Fluids}

To determine rheological behavior of GC-P4 after dilution with fluids that usually presents in the vagina, viscosities and the effect of dilution on gelation were evaluated. Vaginal fluid simulant (VFS) of pH 4.2 and seminal fluid simulant (SFS) of pH 7.7 were prepared as described previously $(26,27)$. GC-P4 hydrogels were diluted with VFS in a biologically relevant ratio of (1:4; VFS: GC-P4) and (1:6; VFS: GC-P4) (28). A fresh set of GC-P4 samples were prepared and diluted with SFS in a biologically relevant ratio of (1:1; SFS: GC-P4) (28). For the measurement of gel behavior following dilution, gel samples were left on the rheometer platform to equilibrate for $60 \mathrm{~s}$ prior to being mixed with either VFS or SFS. Steady shear viscosity step and time sweep analysis were conducted as described earlier.

\section{In Vitro Release of P4 from GC-P4 Hydrogel}

\section{Swelling/Erosion of GC-P4 Hydrogel}

To study the mechanisms of in vitro $\mathrm{P} 4$ release from the GC$\mathrm{P} 4$, change in hydrogel weight as function of time following VFS exposure was measured. One ml of GC-P4 was placed into screw capped vials and incubated at $37^{\circ} \mathrm{C}$. Following gel formation, $0.75 \mathrm{ml}$ VFSs was placed over GC-P4. Vials were then placed on the platform of a MaxQ 4450 Benchtop Incubating Shaker (Thermoscientific, IA, USA). The incubation temperature was maintained at $37^{\circ} \mathrm{C}$. Samples were subjected to a rotation speed of $70 \mathrm{rpm}$ (providing shear rate of $\left.50 \mathrm{~s}^{-1}\right)$. At predetermined time intervals, VFSs were removed by pipette and replace by a fresh solvent. GC-P4 were weighed at each time intervals using a AG104 analytical balance (METTLE TOLEDO, Columbus, OH). The amounts of VFS removed at each time were used to further analyze the percentage of $\mathrm{P} 4$ released from the hydrogel.

\section{Determination of P4 Release from GC-P4 Hydrogel}

To analyze the amount of $\mathrm{P} 4$ release from GC-P4 hydrogel, P4 was extracted from VFS using diethyl ether. Briefly, in a fume hood, $3 \mathrm{ml}$ of diethyl ether were added to the VFSs. Samples were vortexed for 1 minutest at room temperature and then placed in $-20^{\circ} \mathrm{C}$ until complete freezing of the aqueous phase occurred. The organic layer was then removed and the samples were kept in a fume hood until complete evaporation of the organic phase. Samples were then suspended in $80 \mathrm{v} / \mathrm{v} \%$ ethanol and the amount of $\mathrm{P} 4$ was determined (21). Quantitative determination of P4 was conducted using a linear calibration curve between the range of $1.96-62.5 \mu \mathrm{g} / \mathrm{ml}$ and a 0.99 correlation coefficient. 


\section{Reporter Gene Assay}

To confirm the bioactivity of $\mathrm{P} 4$ released from GC-P4 system, the ability of $\mathrm{P} 4$ to induce Progesterone receptor (PR)signal transduction pathways was performed. Briefly, $239 \mathrm{~T}$ cells were seeded in a density of $1.5 \times 10^{6}$ cells / well in a 6-well plate. A plasmid containing $\mathrm{P} 4$ responsive elements (PRE) fused to firefly luciferase (Cignal reporter assay kit, QIAGEN, CA, USA) was transfected into $239 \mathrm{~T}$ (500 ng /well). Transfection was carried out using FuGENE® 6 Transfection Reagent (Promega, WI, USA). 24 h post-transfection, cells were treated with either P4100nm, GC-P4100nm, $\mathrm{GC}$, or no treatment for $18 \mathrm{~h}$. Luciferase activity was measured using Dual-Luciferase Reporter Assay System (Promega, WI, USA) according to manufacture's instruction. Results were represented as Luciferase activity normalized to Renilla luciferase.

\section{In Vitro Safety and Toxicity of GC-P4 Hydrogel}

\section{MTT 3-(4,5-dimethylthiazol-2-yl) -2,5-diphenyltetrazolium Bromide Assay}

To determine GC biocompatibility with vaginal epithelium, VK2/E6E7 cells were seeded in 96-well plate at a density of $5 \times 10^{3}$ cell/well and incubated for $24 \mathrm{~h}$ in a volume of $100 \mu \mathrm{l}$ media/well. Serial dilutions of GC in citrate-phosphate buffer (0.1 M, pH 4.2) were added to the cells and incubated for another $24 \mathrm{~h}$. After exposure, $20 \mu \mathrm{l}$ of $2.5 \mathrm{mg} / \mathrm{ml}$ MTT (Invitrogen, OR, USA) in PBS was added to the cells. The cells were incubated with MTT for $4 \mathrm{~h} 37^{\circ} \mathrm{C}$. MTT solutions were completely removed and $100 \mu \mathrm{l}$ DMSO was added to solubilize formazan crystals. Absorbance was measured at 540 nm using Spectramax 250 microplate reader (Molecular device, CA, USA). Percent viability was calculated from $\left(\mathrm{OD}_{540}\right.$ sample $/ \mathrm{OD}_{540}$ control $) \times 100$, referring to $\mathrm{GC}$ treated and non-treated cells.

\section{Lactobacillus Viability Assay}

To assess the effect of GC on the sustainability of an intact, normal vaginal flora, the viability of Lactobacillus crispatus after the exposure to GG was determined. Bacteria were seeded in a density of $10^{7}$ colony formation units (CFU) / $100 \mu \mathrm{l}$ in 96well plates and incubated with $100 \mu \mathrm{l}$ serial dilutions of $\mathrm{GC}$ at $37^{\circ} \mathrm{C}$ for $24 \mathrm{~h}$. After $24 \mathrm{~h}$ incubation, a $20 \mu \mathrm{l}$ MTS [3-(4,5dimethyl thiazole-2-yl)-5-(3-carboxymethoxyphenyl)-2-(4-sulfonyl) 2H-tetrazolium (Promega, Madison, WI, USA) reagent was added to each well. Absorbance was measured at $490 \mathrm{~nm}$ and the percent viability was calculated from $\left(\mathrm{OD}_{490}\right.$ sample/
$\mathrm{OD}_{490}$ control $) \times 100$, which refers to $\mathrm{GC}$ treated and nontreated bacteria. To confirm the safety of GC in the concentrating used for the GC-P4 formulation, the ability of $5 \%$ GC as well GC-P4 to inhibit the growth of Lactobacillus on an agar plate was tested. A scrap of Lactobacillus crispatus from bacterial broth was directly spread on an MRS agar plate. Each plate was divided into four quarters and $250 \mathrm{ul}$ of the tested material was placed in the center of each quarter. Plates were incubated for $24 \mathrm{~h}$ at $37^{\circ} \mathrm{C}$. The effect of $5 \% \mathrm{GC}$ and $\mathrm{GC}$ $\mathrm{P} 4$ on bacterial growth were evaluated and compared to the effect of both Gynol II ${ }^{\circledR}$ (nonoxynol-9) and Crinone ${ }^{\circledR}$.

\section{Clonogenic Assay}

Human VK2/E6E7 were seeded in six well plates (Transwell@, Costar, NY, USA) in a density of 2000 cells/ well. Cells were incubated in $2 \mathrm{ml}$ Keratinocyte-Serum Free medium until complete cells attachment. Cells were then treated with either 5\% GC, GC-P $4_{200 \mu \mathrm{g}}, \mathrm{P} 4_{200 \mu \mathrm{g}}$, Gynol II® as a positive control, or Crinone $\AA_{200 \mu \mathrm{g}}$, through a $0.4 \mu \mathrm{m}$ polyester transwell membrane for $24 \mathrm{~h}$. In addition, one group of cells was left untreated and served as a blank. Transwells were then removed and cells were cultured for additional 7 days until the formation of visible colonies. Colonies were then fixed for at least $30 \mathrm{~min}$ with a $6 \%$ glutaraldehyde and 0.5 crystal violets mixture. Wells were rinsed under running tap water and numbers of blue visual colonies were quantified with Image J 1.440 software (N.I.H., Bethesda, MD, USA) (size range of $2 \sim 200 \mu \mathrm{m}$ ).

\section{In Vivo Safety and Efficacy of GC-P4 Hydrogel \\ In Vivo Safety of GC-P4 Gel to Vaginal Epithelium}

To investigate the safety of GC-P4 gel when applied to mouse vaginal epithelium in vivo, mice were divided into three groups $(n=2)$, anesthetized by IP injection with Xylazine-Ketamine at dose of $0.1 \mathrm{ml} / 10 \mathrm{~g}$ and treated vaginally with either GC-P4 gel, Gynol II ${ }^{\circledR}$ (positive control), or phosphate buffered saline (PBS) (negative control) once a day for three consecutive days. After $24 \mathrm{~h}$ of administering the last dose, all animals were sacrificed and vaginal tissues were trimmed and fixed in $10 \%$ formalin for $48 \mathrm{~h}$. Tissues were dehydrated in 70\% ethanol and send to Associated Regional and University Pathologists (ARUP) at the University of Utah for Hematoxylin and Eosin staining (H\&E). Histology of vaginal tissues for both treated and control animals were examined by two independent pathologists, using light microscopy at the department of Pathology, University of Utah. 


\section{In Vivo Efficacy of GC-P4 Gel in Estrogen (E2) Induced Endometrial Hyperplasia (EH) Mouse Model}

6-8 week old female $\mathrm{Nu} / \mathrm{Nu}$ mice were divided in to three groups and anesthetized. Doses of subcutaneous estrogen (E2) were administered to mice in all groups to induce EH. One group of mice did not receive $\mathrm{E} 2$ therapy and served as disease negative control. After 4 weeks of E2 treatment and confirmation of simple endometrial hyperplasia (SEH) through histology, one group of animals, which received E2 therapy, received daily intravaginal GC-P4 (60 $\mu \mathrm{g}$ / day) treatment for 2 weeks by restraining the mice in rodent restrainer. The second group of E2 treated mice, received no $\mathrm{P} 4$ treatment and served as disease positive control. In $24 \mathrm{~h}$ of administering the last GC-P4 dose, animals were sacrificed and uterine tissues were trimmed, handled as mentioned earlier, and send to ARUP for H\&E. Histology of GC-P4 treated and nontreated mice uteri were examined by two independent pathologists using light microscopy at the department of Pathology, University of Utah.

\section{Statistical Analysis}

Statistical analysis and plotting graphs were performed using GraphPad Prism software (GraphPad Software Inc. San Diego, CA). All experiments are conducted in triplicate unless indicated otherwise. Results are expressed as mean \pm SEM, and $P<0.05$ was considered significant.

\section{Results}

\section{Glycol Chitin (GC) Hydrogel for Vaginal Application}

Although vaginal $\mathrm{P} 4$ administration has demonstrated promising potency for many obstetrical and gynecological conditions when compared to other routes (oral and IM), environmental limitations such as acidic $\mathrm{pH}$ and the abundance of mucin in the vagina are challenging when aiming at the broader clinical translation of vaginal drug delivery. To confirm that GC hydrogel is capable to successfully overcome these challenges, we began the characterization by first measuring the $90 \% \mathrm{DA} \mathrm{GCs}_{\text {gel }}$ as a function of concentration or $\mathrm{pH}$. Ninety percent DA GC was chosen in this study based on its ability to form a low viscosity solution in room temperature, which easy to handle and to corporate drug into, and having a $\mathrm{T}_{\text {gel }}$ near body temperature using minimum polymer concentration (14). Other DA GC, i.e. 80\%, was tested in the polymer selection process, however showed either no gelation in low concentration, or give high $\mathrm{T}_{\text {gel }}\left(>40^{\circ} \mathrm{C}\right)$ in higher polymer concentration (Figure $\mathrm{S} 2$ ). $\mathrm{T}_{\text {gel }}$ for $\mathrm{GC}$ was found to decrease with increasing $\mathrm{GC}$ concentration, indicating $30.9 \pm 1.6^{\circ} \mathrm{C}$, $28.2 \pm 1^{\circ} \mathrm{C}$, and $23.1 \pm 1.3^{\circ} \mathrm{C}$, at $5,6, \&$ and $7 \%$, respectively (Fig. 1a, Figure S3). In addition, the $\mathrm{T}_{\text {gel }}$ at $5 \%$ demonstrated $30.9 \pm 1.6,26.5 \pm 2.9$, and $15 \pm 1.3^{\circ} \mathrm{C}$ at a $\mathrm{pH}$ of $4.2,6$, and 7.2, respectively (Fig. 1b, Figure S4). Rheological analysis of GC demonstrated a positive rheological synergism parameter $(\Delta G>0)$ that existed between GC and mucin under physiological $\mathrm{pH}(\sim 4.2)$ indicating its mucoadhesive capability as shown in Fig. 1c.

\section{Glycol Chitin-Progesterone (GC-P4) Hydrogel}

Water-soluble amphiphilic polymers have been frequently studied for solubilization of hydrophobic drugs. Therefore, we tested the GC solubilizing capacity of $\mathrm{P} 4$. P4 solubility was found to proportionally increase with increasing $\mathrm{GC}$ concentrations reaching $148.4 \pm 13.8 \mu \mathrm{g} / \mathrm{ml}$ in $5 \% \mathrm{GC}$ (Fig. 2a). This did not exceed the solubility of P4 when using other formulations such as a mixture of PEG400/water (50:50 v/v) (29). To achieve therapeutically relevant amounts, we further increased the amount of $\mathrm{P} 4$ loaded within the gel, and $\mathrm{P} 4$ was added to 5\% GC solution in a concentration that exceeded its solubility. Five percent GC solution containing P4 0.1\%; (w/v) at $\mathrm{pH} 4.2$, which will be referred to as GC-P4 in the rest of this manuscript, demonstrated a slight increase in $\mathrm{T}_{\text {gel }}$ from $30.9 \pm 1.6^{\circ} \mathrm{C}$ to $34.3 \pm 1.6^{\circ} \mathrm{C}$ (Fig. $2 \mathrm{~b}$ ), which was statistically non-significant (NS). Moreover, GC-P4 formed a stable hydrogel in several seconds within vaginal (body) temperature (Fig. 2c).

\section{Mechanical Characteristics of GC-P4 Hydrogel}

Confirming suitable mechanical characteristics equipping our material with necessary properties to withstand the vaginal environment, we studied the dynamics of GC-P4 rheological properties in 25 and $37^{\circ} \mathrm{C}$. Unlike at $25^{\circ} \mathrm{C}$, GC-P4 revealed a solid-like behavior with a rigid three dimensional microstructure under oscillatory stress ranging from 0.5 to $100 \mathrm{~Pa}$ in $37^{\circ} \mathrm{C}$ (Fig. 3a). When measuring critical oscillatory stress (COS), GC-P4 formed a 1.5 times firmer gel than Crinone ${ }^{\circledR}$ as shown in Fig. 3b. In addition, GC-P4 had a dominant elastic property $\left(G^{\prime}>G^{\prime \prime}\right)$ during frequency sweep analyses at $37^{\circ} \mathrm{C}$ (Fig. 3c) and indicated a $\tan \delta=G^{\prime \prime} / G^{\prime}<1$ as shown in Fig. 3d. Where at $25^{\circ} \mathrm{C}, \mathrm{GC}-\mathrm{P} 4$ showed a typical liquid material frequency spectra of $G^{\prime}<G^{\prime \prime}$, and frequency dependent viscoelastic moduli.

\section{GC-P4 Hydrogel in Biologically Relevant Fluids}

Viscosity profiles showed that GC-P4 hydrogel presented a pseudoplastic non-Newtonian behavior (shear thinning) with a 

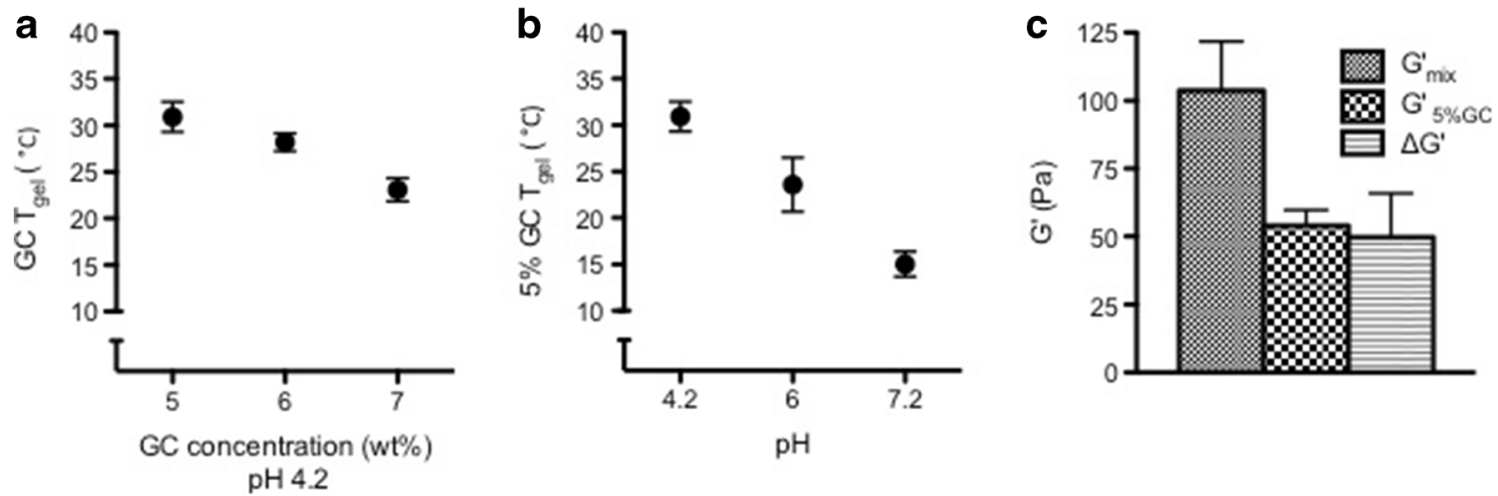

Fig. I Glycol chitin (GC) hydrogel for vaginal application. (a) $\mathrm{GC} \mathrm{T}_{\text {gel, }}$ at $\mathrm{pH} 4.2$ decreased by increasing polymer concentration, and (b) environmental pH in case of 5 wt \% GC. (c) $5 \%$ GC retained mucoadhesive properties detected by a positive value of the interaction parameter $\Delta G$ and a $G_{\text {mix }}^{\prime}>G_{G C}^{\prime}$.

biological relevant shear rate at $37^{\circ} \mathrm{C}$ (Fig. 4a). A significant reduction in the viscosity of $\mathrm{GC}-\mathrm{P} 4$ occurred at $25^{\circ} \mathrm{C}$. Under the influence of relevant biological fluids, GC-P4 showed a slight decrease in viscosities under dilution with VFS (Fig. 4a). However, as expected the viscosity of GC-P4 was significantly decreased after the dilution with a SFS (Fig. 4b). Time sweep analyses also showed destabilized viscoelastic moduli of GC$\mathrm{P} 4$ and a reduction in the magnitude between $G^{\prime}$ and $G^{\prime \prime}$ when diluted with SFS (Fig. 4d). Mimicking prevalent physiological conditions, GC-P4 diluted with VFS clearly yielded a stable gel with constant viscoelastic moduli (Fig. 4c). GC-P4 was capable of maintaining this stable gel state over $12 \mathrm{~h}$ showed in (Figure S5)

\section{In Vitro Release of P4 from GC-P4 Hydrogel}

To determine the mechanisms of $\mathrm{P} 4$ release from GC-P4 and estimate the gel durability, the hydrogel was exposed to VFS at $37^{\circ} \mathrm{C}$, and a shear of $50 \mathrm{~s}^{-1}$ (30). GC-P4 exhibited a $20 \%$ increase in weight, which occurred within the first $30 \mathrm{~min}$ of exposure, followed by a weight decrease. Weight decrease reached up to $50 \%$ of GC-P4's original weight following four hours of exposure to VFS (Fig. 5a). Consequently, 50\% of P4 was released from the hydrogel within the same amount of time (Fig. 5b).

In addition we also investigated the bioactivity of the released $\mathrm{P} 4$ by progesterone receptor $(\mathrm{PR})$ reporter assay capturing only active $\mathrm{P} 4$ binding to $\mathrm{PR}$. P4 released from GC$\mathrm{P} 4_{100 \mathrm{nM}}$ showed comparable activity with free $\mathrm{P} 4_{100 \mathrm{nM}}$ and also demonstrated significant increase in $\mathrm{PR}$ reporter activity compared to $\mathrm{P} 4$ non-treated and 5\% GC only treated cells (Fig. 5c).

\section{In Vitro Safety and Toxicity of GC-P4 Hydrogel}

To assess the safety and toxicity of GC-P4 as a vaginal drug delivery system, cellular and microbial toxicity of GC and GC-P4 to human vaginal epithelial cells as well as normal, physiological vaginal flora were measured. MTT assays showed no toxicity towards the human vaginal epithelial cell line (VK2/E6E7) following exposure to different GC concentrations, indicated by (\%) viability ranging from $84.4 \pm 15.8$ to $107 \pm 22.3$ (NS) when compared to untreated control cells (Fig. 6a).

Lactobacilli act as gatekeepers for the vaginal ecosystem and play a crucial role in protecting the vaginal environment from
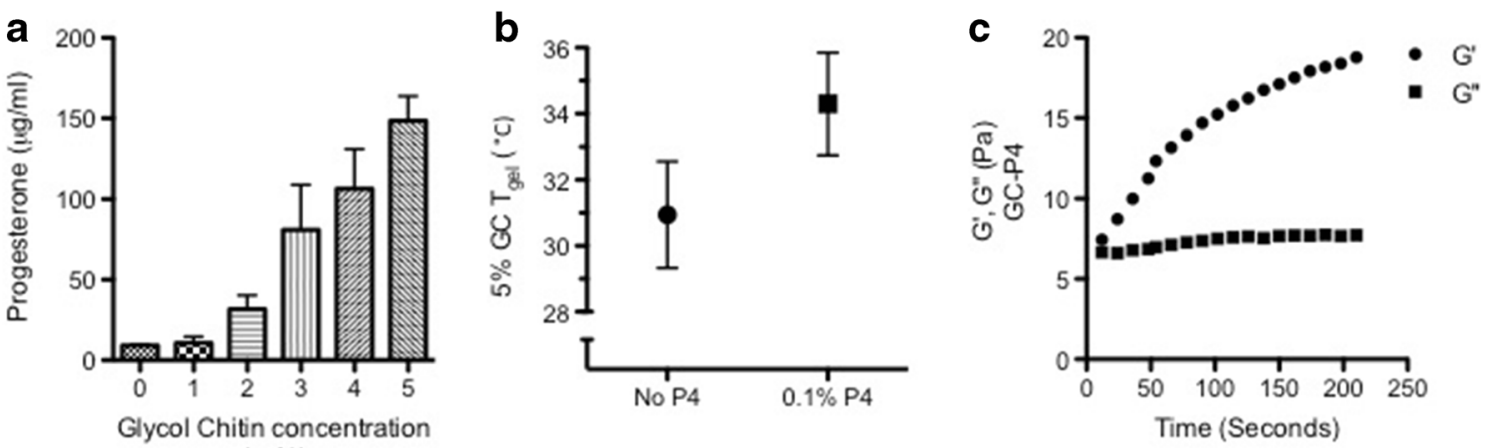

Fig. 2 Glycol chitin-Progesterone (GC-P4) hydrogel. (a) Solubility of P4 in GC solutions. P4 solubility proportionally increased with increasing GC concentration, $(n=4)$. (b) $0.1 \%$, (w/N) P4 loaded into 5\% GC at pH 4.2 (GC-P4) maintains a $T_{\text {gel }}$ near body temperature. (c) Gelation of GC-P4 within seconds after exposure to vaginal temperature $\left(37^{\circ} \mathrm{C}\right)$. 
Fig. 3 Mechanical characteristics of GC-P4 hydrogel. (a) Stress sweep analysis for GC-P4 gel at 25 and $37^{\circ} \mathrm{C}$. (b) $\operatorname{COS}_{\mathrm{GC}-\mathrm{p} 4}>$

$\mathrm{COS}_{\text {Crinone® }}$ indicating that GC-P4 gel is more resistance to external stress, at $37^{\circ} \mathrm{C}$. (c) Frequency spectra in $37^{\circ} \mathrm{C}$ indicated that GCP4 gel exhibited elastic properties in vaginal environment, unlike in $25^{\circ} \mathrm{C}$. (d) $\tan \delta=\left(G^{\prime \prime} / G^{\prime}\right)<$ I for most frequency range for GC-P4 in $37^{\circ} \mathrm{C}$ typical for elastic-solid materials.
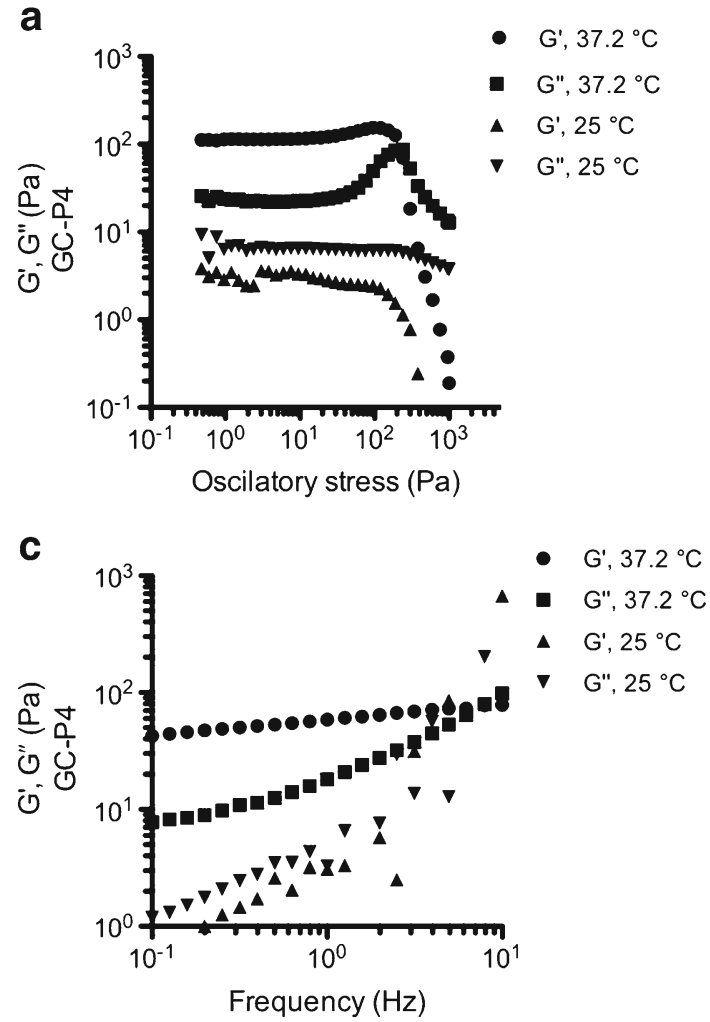
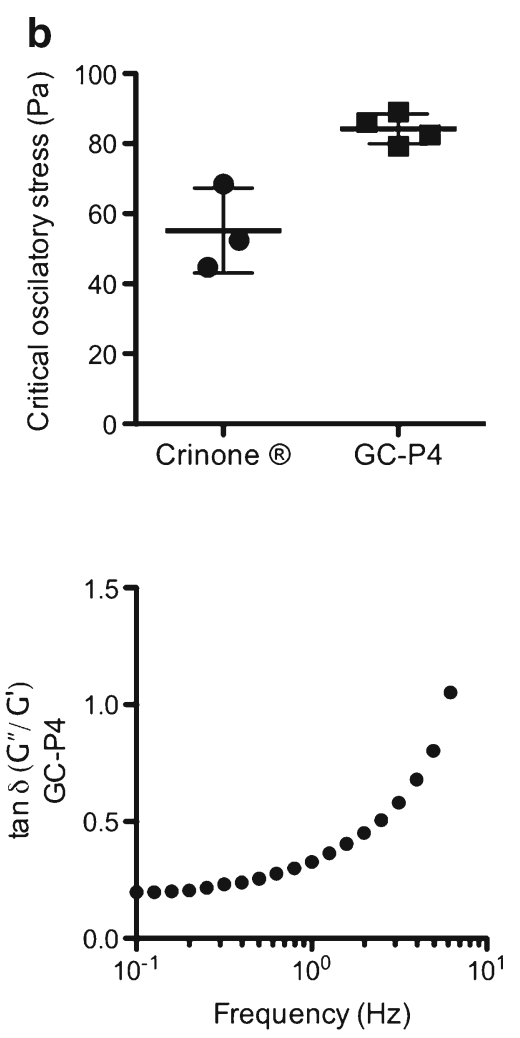

pathogens. MTS assays were performed to evaluate lactobacillus viability following exposure to various GC concentrations. GC did not impact viability of Lactobacilli showing (\%) viability ranging from 95.6 \pm 3.7 to $106.4 \pm 1$ (NS) (Fig. 6b). Further, there was no effect on Lactobacillus growth on the agar plate after exposure to $5 \%$ GC or GC-P4. However, Crinone ${ }^{\circledR}$
Fig. 4 GC-P4 hydrogel in biologically relevant fluids. (a) GCP4 presented a non-Newtonian viscosity (shear thinning) in shear rate of $0.1-100 \mathrm{~s}^{-1} 37^{\circ} \mathrm{C}$, and a significant reduction of $\mathrm{GC}$ viscosity at $25^{\circ} \mathrm{C}$. (b) GC-P4 viscosity nonsignificantly decreased after 1:6 dilution with VFS and significantly decreased after I:4 dilution. (c) Dilution with SFS had a greater impact on GC-P4 viscosity. (d) Representative figures of GC-P4 time sweep analyses after dilution with biological relevant fluids $(n=2)$. No effect on gel quality occurred after I:4 dilution of GC-P4 with VFS, however, a decrease in gel quality was found after I:I dilution with SFS detected by unstable and closer $G^{\prime}$ and $G^{\prime \prime}$ values.
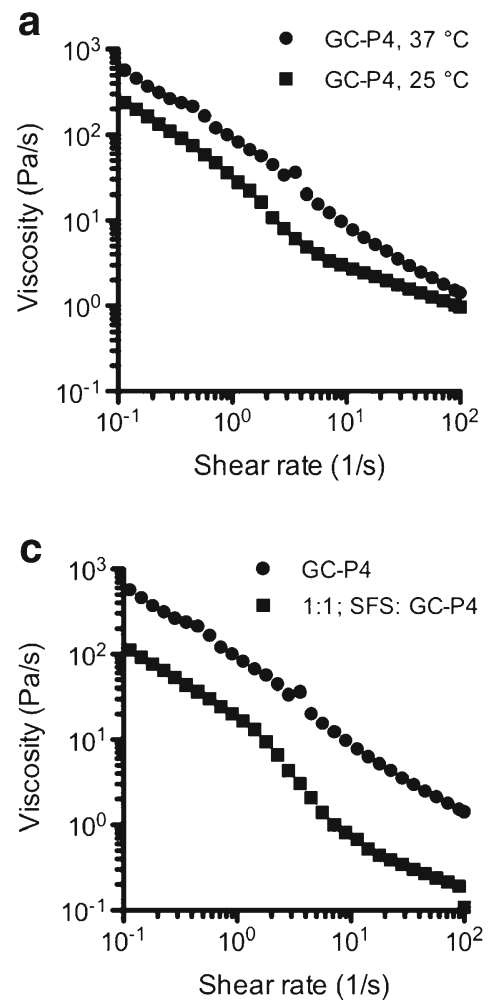
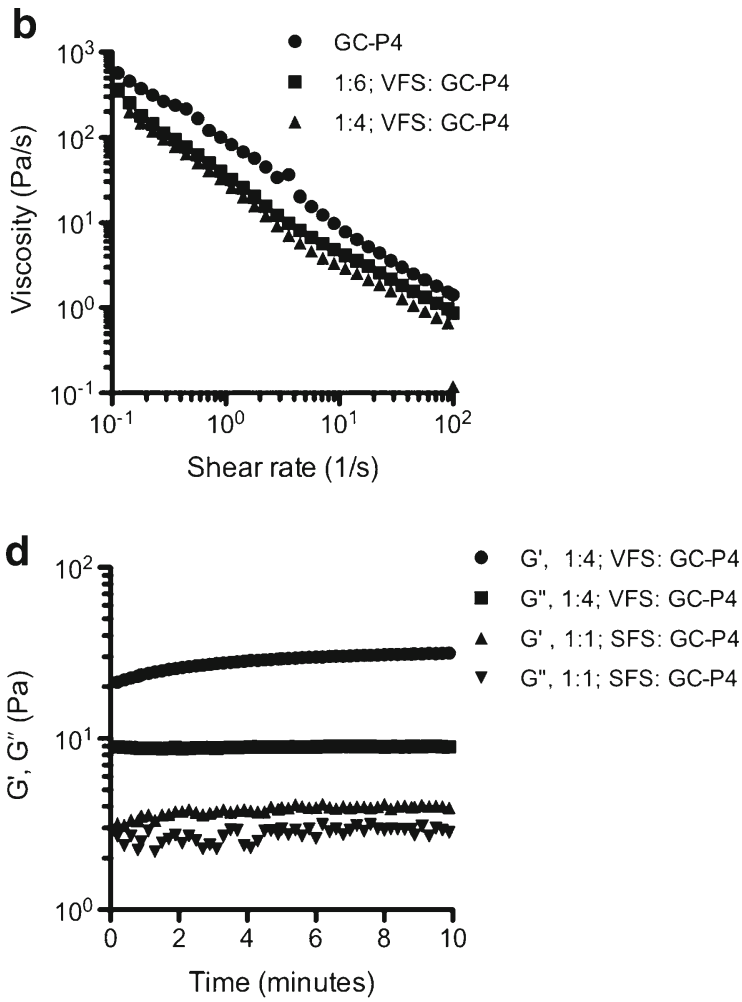
Fig. 5 In vitro release profile and bioactivity of P4 released from GCP4 hydrogel. (a) Swelling of GC-P4 gel occurred within the first 30 min after gel exposure to VFS at $37^{\circ} \mathrm{C}$, followed by decreased in weight (erosion) $(n=4)$. (b) Up to $50 \%$ of P4 dose was released within $4 \mathrm{~h}$ of exposure to VFS at $37^{\circ} \mathrm{C}(n=4)$. (c) Increase in PR transcriptional activity after treatment with GC-P4 I $00 n M_{1}$ measured in RLU with no significance different to RLU of $\mathrm{P}_{\text {I } 00 \mathrm{nM}}$ treated cells.
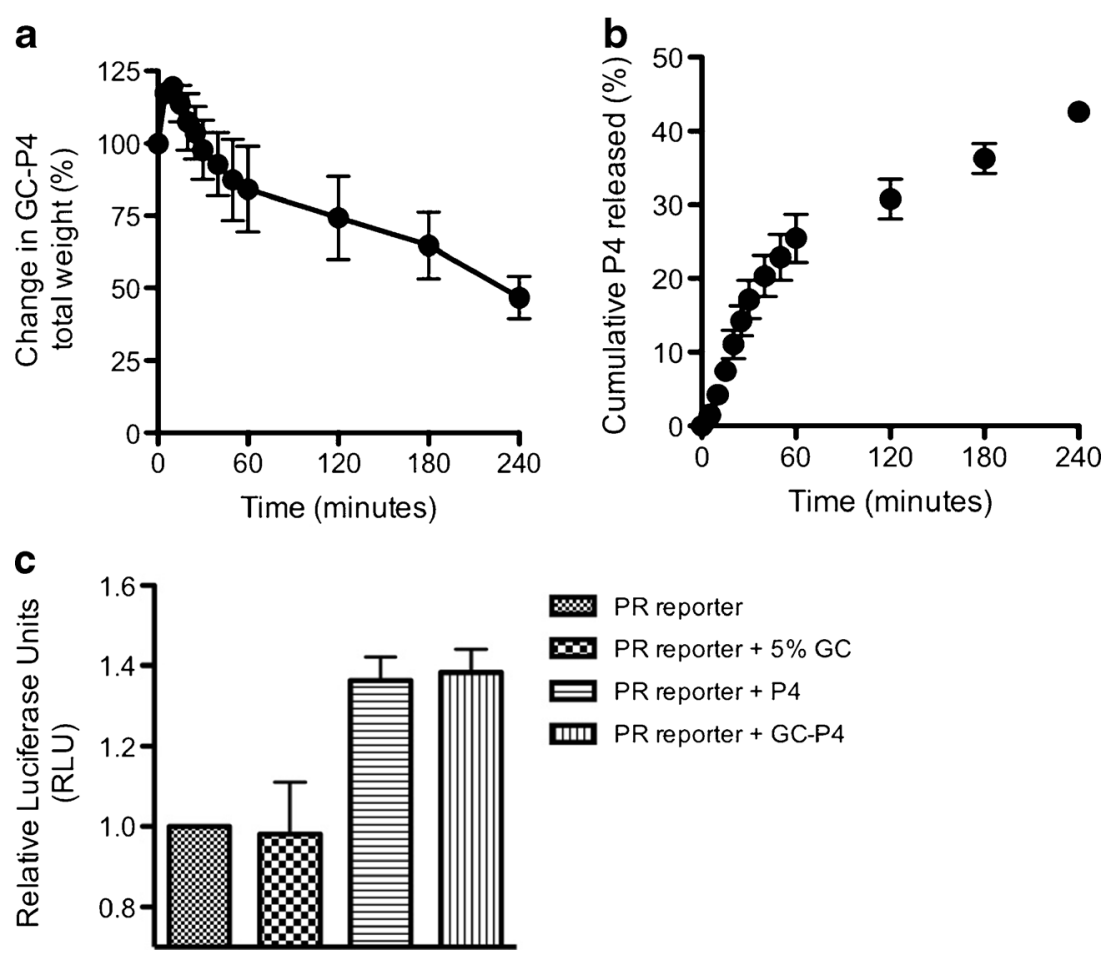

and Gynol II ${ }^{\circledR}$ inhibited the growth of bacteria on the agar plate (Figure S6).

In addition, clonogenic assays demonstrated that the number of VK2/E6E7 cell colonies following exposures to $5 \%$ GC was comparable to number of colonies in the non-treated group. Although there was a slight decrease in the number of $\mathrm{VK} 2 / \mathrm{E} 6 \mathrm{E} 7$ colonies treated with GC-P4, the formation of colonies were significantly reduced after treatment with Crinone ${ }^{\circledR}$ or Gynol II ${ }^{\circledR}$ (Fig. 6c, Figure S7).
Fig. 6 In vitro safety and toxicity of GC-P4 hydrogel. (a) MTT assays indicated no difference in percent viability in VK2/E6E7 cell after treatment with GC solutions. (b) No difference between \% viability of Lactobacillus crispatus after treatment with different concentration of GC compared to non-treated cells. (c) VK2/E6E7 cell lines retained their ability to form colonies after treatment with 5\% GC and GC-P4 $200 \mu \mathrm{g}$ gel compared to $\mathrm{P} 4_{200 \mu \mathrm{g}}$ alone, Gynol II ${ }^{\circledR}$, and Crinone $\AA_{200 \mu \mathrm{g}}$.

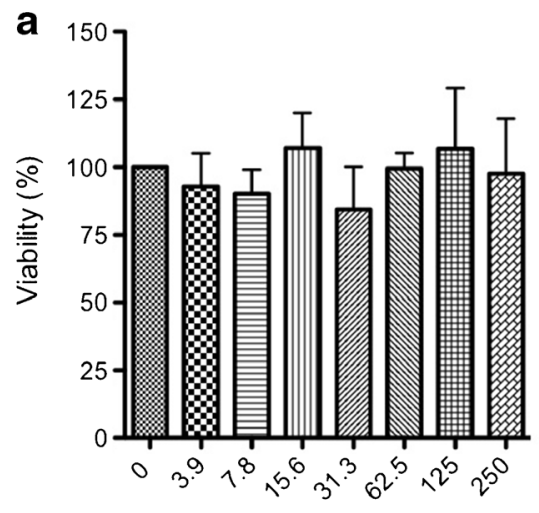

Glycol chitin ( $\mu \mathrm{g} / \mathrm{ml})$

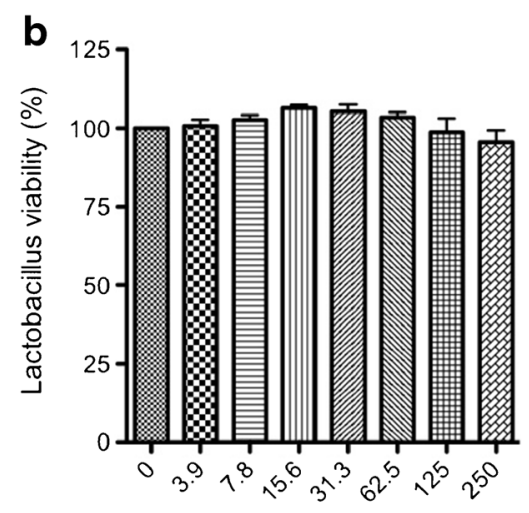

Glycol chitin $(\mu \mathrm{g} / \mathrm{ml})$

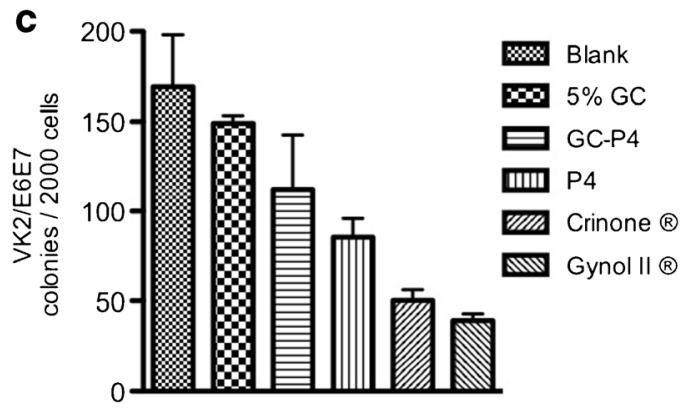




\section{In Vivo Safety and Efficacy of GC-P4 Hydrogel}

To evaluate the safety and efficacy of GC-P4 following vaginal administration in vivo, GC-P4 was evaluated in a mouse model. Six to eight week old female $\mathrm{Nu} / \mathrm{Nu}$ mice were repeatedly treated by vaginal administration of either GC-P4, Gynol II ${ }^{\circledR}$ (positive control), or PBS (negative control). Histopathological tissue evaluation was determinedas study endpoint. Within $24 \mathrm{~h}$ following the last dose, animals were sacrificed, tissues were harvested and vaginal epithelium underwent $\mathrm{H} \& \mathrm{E}$ staining followed by independent histopathological evaluation through two different anatomical pathologists. GC-P4 was determined to be safe to administer to murine vaginal epithelium in vivo. Only negligible, non-significant, transient signs of acute inflammation were observed when compared to a control group treated with PBS (Fig. 7a top and bottom). In contrast, treatment with Gynol II® showed ubiquitous signs of chronic vaginal tissue inflammation accompanied by massive death of squamous cells as well as a significant increase in neutrophils were observed (Fig. 7a middle).
To further determine the efficacy of GC-P4 in vivo, we designed and developed an E2 induced EH mouse model in which mice were exposed to a continuous dose of exogenous E2 over time. Female $6-8$ week old $\mathrm{Nu} / \mathrm{Nu}$ mice were assigned randomly to receive no E2 or GC-P4 $60 \mu \mathrm{g}$ (normal endometrium), subcutaneous (s.c.) E2 only (disease control), or s.c. E2 followed by GC-P4 $60 \mu \mathrm{g}$ (treatment group). GC-P4 $60 \mu \mathrm{g}$ was administered vaginally once daily for 2 weeks after confirming the successful development SEH. Within $24 \mathrm{~h}$ after receiving the last dose mice were sacrificed. Endometrial tissues were harvested and underwent $\mathrm{H} \& \mathrm{E}$ staining followed by histopathological evaluation. As expected, normal, untreated mouse endometrium showed small tubular glands, some in clusters, but overall with abundant intervening stroma representative of healthy endometrium. Occasional mitotic figures were noted in endometrial glandular cells, consistent with proliferative phase endometrium (Fig. 7b top). Endometrial samples derived from mice that were exposed to E2 showed the development of markedly crowded glands with complex architecture, lined by cells with
Fig. 7 In vivo safety and efficacy of GC-P4 hydrogel. (a) Hematoxylin and Eosin staining (H\&E) PBS (Top) with Intact squamous cells (Keratinocytes) and rare Neutrophil cells, Gynol II ${ }^{\circledR}$ gel (Middle) arrows indicate massive cell death of squamous cells (Keratinocytes), and GC-P4 (bottom) arrow indicate minimal cell death of Keratinocytes, X200. (b) Normal, murine endometrium demonstrates small tubular glands, some in clusters, but overall with abundant intervening stroma $\times 100$ (top). E2 Effect, no GC-P4 treatment X400 (middle) demonstrating complex atypical hyperplasia. Following initial daily treatment with vaginal GC-P4 $60 \mu \mathrm{g}$ for 2 weeks, the features are consistent with simple non-atypical hyperplasia X200 (bottom). Scale bar $=100 \mathrm{um}$. a
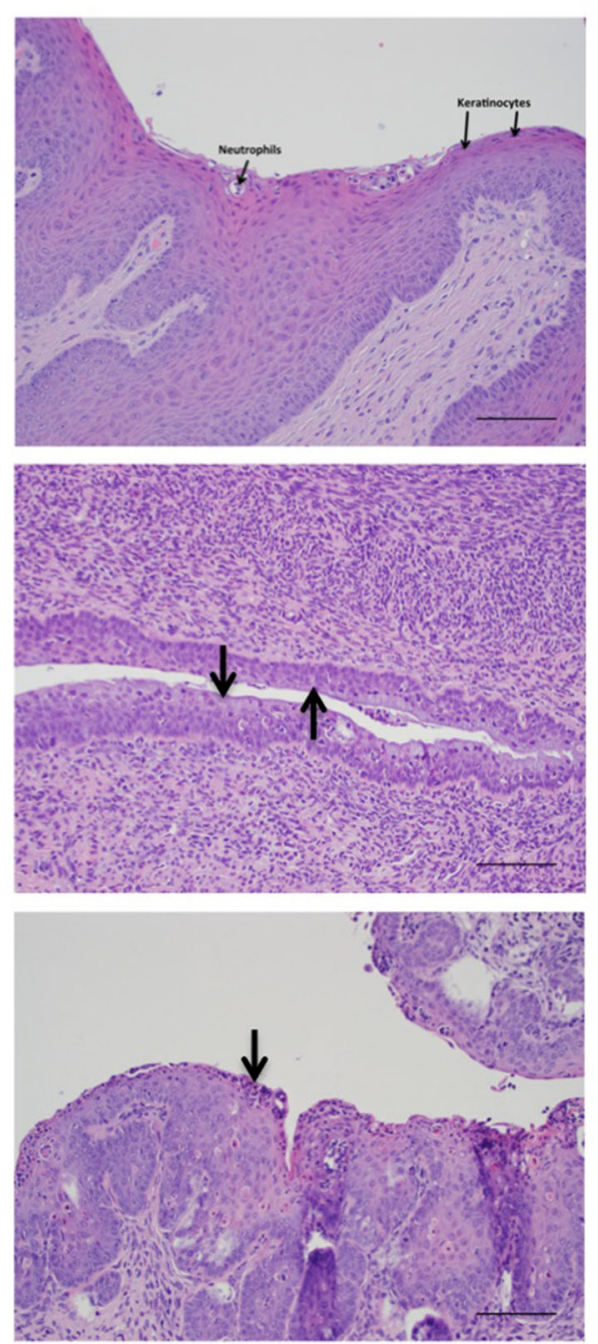

b
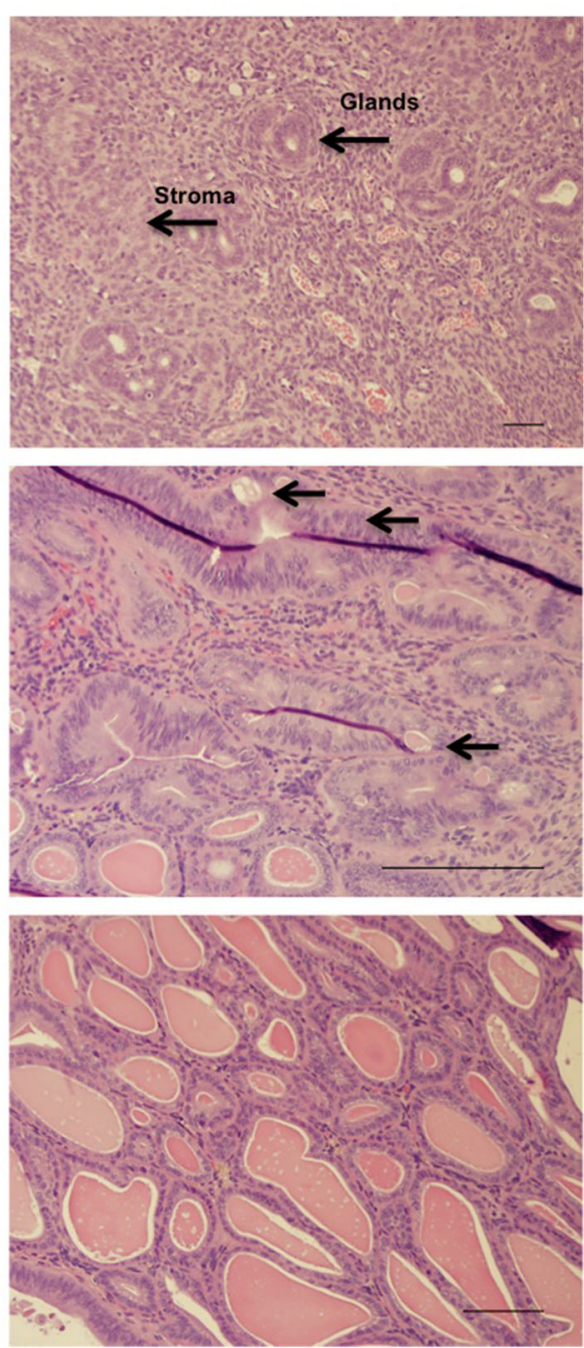
enlarged, atypical nuclei exhibiting a loss of polarity and variably conspicuous nucleoli, characteristic of complex atypical endometrial hyperplasia (CAEH) (Fig. 7b middle). The endometrium of mice treated with GC-P4 $40 \mu \mathrm{g}$ following E2based establishment of non-atypical SEH contained crowded, cystically dilated glands lined by cytologically unremarkable proliferating glandular cells, all characteristic for SEH (Fig. 7b bottom). Tissue histology identified clear differences in between GC-P4 $60 \mu \mathrm{g}$ treated and non-treated hyperplastic endometrium

\section{Discussion}

The goal of this study is to improve and optimize vaginal $\mathrm{P} 4$ delivery by designing a new thermosensitive, mucoadhesive gel using GC, a chitosan derivative, as the delivery platform. The results demonstrate that GC-P4 is a promising $\mathrm{P} 4-$ delivery system suitable for vaginal application. GC-P4 gel is stable in a vaginal like environment, potentially safe for vaginal tissues, and demonstrates efficacy against the development of CAEH.

Although various hydrogels, represented by copolymers of poly-(ethylene oxide), poly-(propylene oxide), and copolymer of $\mathcal{N}$-isopropylacrylamide show promising properties for biomedical applications, their clinical use has been limited by their lack of biodegradability, biocompatibility, and physical stability $(31,32)$. Therefore, there has been a continuing effort to develop new bio-functional polymers with improved biocompatibility and physico-chemical properties. Previously, we have reported a novel thermo-reversible sol-gel transition polymer, glycol chitin (GC), which is synthesized by a simple $\mathcal{N}$-acetylation reaction of glycol chitosan (14). In contrast to typical sol-gel transition polymers structurally based on synthetic block copolymer structures, GC is an amphiphilic chitosan-based polymer with good biocompatibility and biodegradability. It is one of few polysaccharide-based polymers autonomously showing a negative thermosensitive sol-gel transition around body temperature without involvement of any crosslinking, grafting or blending systems. In this work, we report for the first time the utilization of GC thermosesitve polymer as a vaginal drug delivery vehicle for $\mathrm{P} 4$. Therefore we, evaluated the behavior of GC and GC-P4 in vaginal like environment as described here

Five percent GC of $90 \%$ DA used in this study, exhibited stable gelation near body temperature. Moreover, environmental $\mathrm{pH}$ appeared to be another factor influencing $\mathrm{GC}$ $\mathrm{T}_{\text {gel }}$. Since the $\mathrm{pKa}$ of the residual amine groups on GC backbone is $\sim 6.84$, ionization of these amines take place at lower $\mathrm{pH}$ inducing the repulsion between polymer chains (33). Thus, increasing $\mathrm{T}_{\text {gel }}$. On the other hand, association of polymer chains takes place in a higher $\mathrm{pH}(\sim 7.2)$ leading to a reduction in $\mathrm{T}_{\text {gel }}$. These results indicate the 5\% GC at $\mathrm{pH} 4.2$ forms a gel near body temperature and vaginal $\mathrm{pH}$, making it a suitable candidate for vaginal application. 5\% GC prepared in $\mathrm{pH} 4.2$ can maintain its physical stability (i.e. appearance and transparency) after being stored at $4^{\circ} \mathrm{C}$ for several months (Figure S8)

We have also confirmed the mucoadhesive ability of GC based using a rheological synergism evaluation. It was reported that free amine groups on chitosan backbones are the main driving force for mucoadhesion (16). However, GC used in this study ( $\approx 90 \%$ degree of acetylation) only exhibits a fairly low number of free amine groups when compared to chitosan, yet still maintained its advantageous mucoadhesive properties (14). We suggest that thermosensitivity of the hydrogel might be contributed to its mucoadhesion. Thermosensitivity could increase the interaction time between GC and the mucinous, vaginal surface probably providing an enhanced establishment of mucoadhesive forces. Unlike other vaginal formulations, which were occasionally reported to melt and leak at body temperature, GC maintains its physical stability within the vaginal environment $(2,12)$. Thus, reducing undesirable vaginal discharges responsible for vaginal and vulvar irritations, possible yeast super infection, and ensuring accurate dosing (3,34).

It is known that some amphiphilic polymers have the ability to enhance the solubility of hydrophobic drugs by forming micelle-like aggregates in aqueous media with hydrophobic domains favoring the partitioning of hydrophobic agents $(14,15)$. Despite the significant enhancement of the aqueous solubility of $\mathrm{P} 4$ by $\mathrm{GC}$, the enhancement was still in the range of micrograms and similar to other current methods used to enhance P4 solubility such as using PEG 400: water (1:1) mixture. Since the therapeutic effects of $\mathrm{P} 4$ are seen in the milligram dose range, we attempted to increase the amount of loaded P4 in our system $(29,35)$. Several alternative methods have been used to enhance the loaded amount of hydrophobic agents into thermosensitive gels, including dispersing the desired drug to a concentration that exceeds its solubility $(9,36)$. It was reported that saturating extramicellar channels in polymeric hydrogels with drug particles favors the controlled release of such drug without significantly altering $\mathrm{T}_{\text {gel }}(36)$. Therefore, we developed a dispersion system of $0.1 \%$; (w/v) $\mathrm{P} 4$ into 5\% GC at $\mathrm{pH} 4.2$ (GC-P4), which maintained an acceptable $\mathrm{T}_{\text {gel }}$ for mucosal application and thermosensitive properties of the hydrogel (10).

The GC-P4 system described herein has shown several favorable rheological characteristics such as stability and spreadability in vaginal like environment. Here, we showed that GC-P4 microstructure is more resistant to external stress and less prone to liquefy under physiological conditions compared to Crinone ${ }^{\circledR}$, a commercially available $\mathrm{P} 4$ gel. In addition, the preferred shear thinning, non-Newtonian behavior that GC-P4 retained under increasing shear indicates a 
satisfactory distribution across vaginal walls important for an equal coating for most of the vaginal surface (24). Besides sheering, there are several other factors in the vagina that can contribute to gel flow behavior and distribution. For example, the presence of VFS and SFS can lead to a change in gel-viscosity through diluting the formulation. Despite the dilution of GC-P4 by VFS, the hydrogel still maintains suitable viscosities. However, it seems that the viscosity of GC-P4 drastically decreases in the presence of SFS. It was reported that viscosities of chitosan-based gels decrease by decreasing the final polymer concentration, due to reducing intermolecular entanglements between polymer chains and increasing their free movements (37). Since the dilution of GC-P4 with SFS was in 1:1 ratio resembling physiological volume of semen, we expected to see a significant reduction in viscosity and gel quality compared to dilution with VFS. Therefore, we suggest that the application of GC-P4 is not suitable in the presence of semen such as immediately prior or shortly after vaginal intercourse due to excessive dilution and possible leaking of the formulation.

Stability and durability of a formulation in the vagina are also crucial allowing an effective release time for the loaded active ingredients (30). After exposure to VFS, GC-P4 showed gradual reduction in gel weight due to polymer chains dissolution (erosion) following initial stage of polymer chain relaxation (swelling). These finding suggest that drug release may be governed by $\mathrm{P} 4$ diffusion out of the gel coupled with GC erosion, typically seen with release mechanisms of drug from hydrogels (38). The physical presence of GC-P4 hydrogel in vitro even after $4 \mathrm{~h}$ post exposure to VFS might suggest an extended residence time, due to both its mucoadhesive and thermosensitive properties. Extended residence times can play a crucial role in reducing the frequency of administration required for an effective treatment, and crucial factor to favorably enhancing patient compliance (9). In this case, GC-P4's provided a controlled-release for P4 liberating up to $50 \%$ of the loaded drug within the first four hours post exposure to vaginal like conditions. Controlled-release systems usually require less amounts of drug to achieve the desired therapeutic effect, possibly reducing the cost of therapy (39). We expect that as the erosion process of GC-P4 hydrogel continues over time, more drug will be liberated in a controlled manner providing an effective absorption and a steady P4 tissue concentration, until a phase of rapid release of drug due to the erosion of the final layer of polymeric gel. Although the percentage of cumulative $\mathrm{P} 4$ released matches the total percentage of loss in GC-P4 weight, we wanted to exclude the possibility of $\mathrm{P} 4$ inactivation either by the GC system or other factors. PR-reporter assays show that P4 successfully maintains its bioactivity following its released from GC-P4, which implies that GC provides a compatible medium for $\mathrm{P} 4$ without hampering its bioactivity. These results demonstrate that GC-P4 is indeed a stable hydrogel capable to release biologically active $\mathrm{P} 4$ into the vaginal environment.
Another prerequisite for an effective and safe vaginal formulation is its ability to not interfere with the vaginal mucosal integrity and the vaginal ecology (40). Vaginal formulations that are either toxic or non-compatible with the vaginal epithelium can cause local irritation and are associated with increased inflammation and infection rates, complications and hence treatment costs $(2,13)$. We showed that GC is safe to vaginal epithelial tissue and does not cause any apparent disturbance to the vaginal flora. Higher degrees of acetylation may be contributing to GC's superior safety profile respective to vaginal tissues. Although chitosan is not known to exhibit increased tissue toxicity, it still may hold potential toxicity based on its amount of cationic surface groups (41). Chargeto-charge interactions between cationic materials and anionic cellular membranes can potentially result in cellular membrane damage (41). Therefore, masking cationic charges by acetylating amine groups may explain the low toxicity of GC. A head to head comparison of GC-P4 with the Crinone $\mathbb{R}$, a commercially available vaginal $\mathrm{P} 4$ formulation, using Clonogenic assay revealed a significant decrease in viable cell colonies after exposure to Crinone ${ }^{\circledR}$. This may be due to some of Crinone's ${ }^{\circledR}$ ingredients, such as sorbic acid known to cause tissue irritation (42). Whereas only a slight impact on colony numbers could be observed after GC-P4 exposure, implying the relative safety of GC-P4 to vaginal mucosa. Similar results were found with bacterial growth inhibition assay, proving the safety of 5\% GC and GC-P4 to vaginal flora.

The in vitro safety and biocompatibility of GC-P4 to the vaginal environment was further confirmed in vivo using a Female $\mathrm{Nu} / \mathrm{Nu}$ (6-8 week old) mouse model. Mouse models are being commonly used as a suitable and economical alternative for the preclinical assessment of safety and efficacy of novel vaginal formulations (43). In direct comparison to Gynol II ${ }^{\circledR}$, which exhibited significant toxicity to the mouse vaginal epithelium in viwo presented by signs of chronic irreversible inflammation, massive cell death of squamous cells, and neutrophil infiltration, histopathological evaluation of the mouse vaginal epithelium after the application of GC-P4 showed almost no signs of toxicity with only minimal and reversible inflammation spontaneously resolving $(44,45)$. With a favorable outcome of first in vivo studies confirming the safety of GC-P4 including multiple applications, additional testing for signs of chronic toxicity needs to be confirmed in future studies. To assess GC-P4's efficacy in vivo, an E2 induced EH mouse model was used. Mice exposed to continuous doses of E2 developed SEH after around 4 weeks, which then after two additional weeks will advance to complex atypical $\mathrm{EH}$ $(\mathrm{CAEH})$. No disease progression to $\mathrm{CAEH}$ was observed to occur after 2 weeks of GC-P4 treatment. This finding was confirmed based on histo-pathological tissue analyses affirming only signs of SEH without any forms of atypia. On the other hand, untreated mice indeed progressed from $\mathrm{SEH}$ to $\mathrm{CAEH}$ and some cases even advanced all the way to 
borderline EC. Therefore, we suggest that $\mathrm{P} 4$ released from GC-P4 was able to minimize the proliferative action of $\mathrm{E} 2$ on the murine endometrium preventing the progression of $\mathrm{SEH}$ to $\mathrm{CAEH}$ or even EC. With the initial very promising efficacy, additional in vivo animal dose and frequency-finding studies are still required.

\section{Conclusion}

The aim of this work was to improve and optimize the vaginal delivery of $\mathrm{P} 4$ by designing a new bio-functional hydrogel formulation equipped with thermosensitive and mucoadhesive characteristics empowering this new formulation to successfully overcome limitations of currently available vaginal $\mathrm{P} 4$ dosage forms. GC-P4 hydrogel; 5\% GC at pH 4.2 loaded with $0.1 \%$ $\mathrm{P} 4$, showed a desired sol-gel transition near body temperature forming and maintaining a stable, gel with desirable flow behavior in the challenging vaginal environment. Although viscosity was found to decrease after dilution with certain biological fluids, GC-P4 gel was still able to maintain a satisfactory gel status after exposure to VFS. However, GC-P4 gel administration immediately prior or after vaginal intercourse may not be recommended due to possibly impacting GC-P4's performance and efficacy. GC-P4 gel is capable of prolonged residence in and exhibits an extended, continued and controlled release of $\mathrm{P} 4$. This new formulation has proven to be safe for application to the vaginal epithelium in vitro as well as in vivo without causing tissue toxicity or irritation even after repeated application. Furthermore, initial in vivo efficacy studies in an EH mouse model revealed the ability of GC-P4 to prevent the progression of $\mathrm{EH}$ from $\mathrm{SEH}$ to $\mathrm{CAEH}$. These results therefore indicate that the $\mathrm{GC}-\mathrm{P} 4$ formulation is a promising alternative to current vaginal $\mathrm{P} 4$ formulations

\section{ACKNOWLEDGMENTS AND DISCLOSURES}

This research was supported in part by a Faculty and Creative grant from the University of Utah, as well as the Department of Obstetrics and Gynecology at the University of Utah. We would like to thank Dr. Patrick Kiser, Associate Professor, Biomedical Engineering, Northwestern university and Howard Y. Lakougna, Graduate Research Assistant, Bioengineering, University of Utah, for use of the rheometer and guidance in obtaining rheological data. Further, we would like to acknowledge Dr. Rachel Factor's (Pathology, University of Utah) insights and valubale discussions.

Open Access This article is distributed under the terms of the Creative Commons Attribution License which permits any use, distribution, and reproduction in any medium, provided the original author(s) and the source are credited.

\section{REFERENCES}

1. Graham JD, Clarke CL. Physiological action of progesterone in target tissues. Endocr Rev. 1997;18(4):502-19.

2. Norwitz ER, Caughey AB. Progesterone supplementation and the prevention of preterm birth. Rev Obstet Gynecol. 201 1;4(2):60-72.

3. Hassan SS, Romero R, Vidyadhari D, Fusey S, Baxter JK, Khandelwal M, et al. Vaginal progesterone reduces the rate of preterm birth in women with a sonographic short cervix: a multicenter, randomized, double-blind, placebo-controlled trial. Ultrasound Obstet Gynecol. 2011;38(1):18-31.

4. Moskowitz D. A comprehensive review of the safety and efficacy of bioidentical hormones for the management of menopause and related health risks. Altern Med Rev J Clin Ther. 2006;11(3):208-23.

5. Reed SD, Voigt LF, Newton KM, Garcia RH, Allison HK, Epplein $\mathrm{M}$, et al. Progestin therapy of complex endometrial hyperplasia with and without atypia. Obstet Gynecol. 2009;113(3):655-62.

6. Valenta C, Kast GE, Harich I, Bernkop-Schnurch A. Development and in vitro evaluation of a mucoadhesive vaginal delivery system for progesterone. J Control Release Off J Control Release Soc. 2001;77(3):323-32.

7. Victor A, Johansson ED. Pharmacokinetic observations on medroxyprogesterone acetate administered orally and intravaginally. Contraception. 1976;14(3):319-29.

8. Silverberg KM, Vaughn TC, Hansard LJ, Burger NZ, Minter T. Vaginal (Crinone 8\%) gel vs. intramuscular progesterone in oil for luteal phase support in in vitro fertilization: a large prospective trial. Fertil Steril. 2012;97(2):344-8.

9. Bilensoy E, Çırpanlı Y, Şen M, Doğan AL, Çalış S. Thermosensitive mucoadhesive gel formulation loaded with 5-Fu: cyclodextrin complex for HPV-induced cervical cancer. J Incl Phenom Macrocycl Chem. 2007;57(1-4):363-70.

10. el Ibrahim SA, Ismail S, Fetih G, Shaaban O, Hassanein K, Abdellah NH. Development and characterization of thermosensitive pluronicbased metronidazole in situ gelling formulations for vaginal application. Acta Pharm. 2012;62(1):59-70.

11. De Ziegler D, Bulletti C, De Monstier B, Jaaskelainen AS. The first uterine pass effect. Ann N Y Acad Sci. 1997;828:291-9.

12. Baloglu E, Senyigit ZA, Karavana SY, Bernkop-Schnurch A. Strategies to prolong the intravaginal residence time of drug delivery systems. J Pharm Pharm Sci Publ Can Soc Pharm Sci Soc Can Sci Pharm. 2009;12(3):312-36.

13. Stadtmauer L, Silverberg KM, Ginsburg ES, Weiss H, Howard B. Progesterone vaginal ring versus vaginal gel for luteal support with in vitro fertilization: a randomized comparative study. Fertil Steril. 2013.

14. Li Z, Cho S, Kwon IC, Janat-Amsbury MM, Huh KM. Preparation and characterization of glycol chitin as a new thermogelling polymer for biomedical applications. Carbohydr Polym. 2013;92(2):2267-75.

15. Qu X, Khutoryanskiy VV, Stewart A, Rahman S, PapahadjopoulosSternberg B, Dufes C, et al. Carbohydrate-based micelle clusters which enhance hydrophobic drug bioavailability by up to 1 order of magnitude. Biomacromolecules. 2006;7(12):3452-9.

16. Sogias IA, Williams AC, Khutoryanskiy VV. Why is chitosan mucoadhesive? Biomacromolecules. 2008;9(7):1837-42.

17. Choi HG, Jung JH, Ryu JM, Yoon SJ, Oh YK, Kim JK. Development of in situ-gelling and mucoadhesive acetaminophen liquid suppository. Int J Pharm. 1998;165(1):33-44.

18. Madsen F, Eberth K, Smart JD. A rheological examination of the mucoadhesive/mucus interaction: the effect of mucoadhesive type and concentration. J Control Release Off J Control Release Soc. 1998;50(1-3):167-78.

19. Riley RG, Smart JD, Tsibouklis J, Dettmar PW, Hampson F, Davis $\mathrm{JA}$, et al. An investigation of mucus/polymer rheological synergism 
using synthesised and characterised poly(acrylic acid)s. Int J Pharm. 2001;217(1-2):87-100.

20. Hägerström H, Edsman K. Limitations of the rheological mucoadhesion method: the effect of the choice of conditions and the rheological synergism parameter. EurJ Pharm Sci. 2003;18(5):349-57.

21. Maliwal D, Jain P, Jain A, Patidar V. Determination of progesterone in capsules by high-performance liquid chromatography and UVspectrophotometry. J Young Pharmacists. 2009;1(4):371-4.

22. Herh P, Tkachuk J, Wu SG, Bernzen M, Rudolph B. The rheology of pharmaceutical and cosmetic semisolids. Am Lab. 1998:12-4.

23. Chang JY, Oh YK, Choi HG, Kim YB, Kim CK. Rheological evaluation of thermosensitive and mucoadhesive vaginal gels in physiological conditions. Int J Pharm. 2002;241(1):155-63.

24. das Neves J, da Silva MV, Goncalves MP, Amaral MH, Bahia MF. Rheological properties of vaginal hydrophilic polymer gels. Curr Drug Deliv. 2009;6(1):83-92.

25. Lai BE, Xie YQ Lavine ML, Szeri AJ, Owen DH, Katz DF. Dilution of microbicide gels with vaginal fluid and semen simulants: effect on rheological properties and coating flow. J Pharm Sci. 2008;97(2): 1030-8.

26. Owen DH, Katz DF. A vaginal fluid simulant. Contraception. 1999;59(2):91-5.

27. Owen DH, Katz DF. A review of the physical and chemical properties of human semen and the formulation of a semen simulant. J Androl. 2005;26(4):459-69.

28. Owen DH, Peters JJ, Katz DF. Rheological properties of contraceptive gels. Contraception. 2000;62(6):321-6.

29. Nandi I, Bateson M, Bari M, Joshi HN. Synergistic effect of PEG-400 and cyclodextrin to enhance solubility of progesterone. AAPS PharmSciTech. 2003;4(1):E1.

30. Geonnotti AR, Peters JJ, Katz DF. Erosion of microbicide formulation coating layers: effects of contact and shearing with vaginal fluid or semen. J Pharm Sci. 2005;94(8):1705-12.

31. Jeong B, Bae YH, Lee DS, Kim SW. Biodegradable block copolymers as injectable drug-delivery systems. Nature. 1997;388(6645):860-2.

32. Bae YH, Okano T, Hsu R, Kim SW. Thermo-sensitive polymers as on-off switches for drug release. Makromol Chem Rapid Commun. 1987;8(10):481-5.

33. Wang QZ, Chen XG, Liu N, Wang SX, Liu CS, Meng XH, et al. Protonation constants of chitosan with different molecular weight and degree of deacetylation. Carbohydr Polym. 2006;65(2):194-201.
34. O'Brien JM, Adair CD, Lewis DF, Hall DR, Defranco EA, Fusey S, et al. Progesterone vaginal gel for the reduction of recurrent preterm birth: primary results from a randomized, double-blind, placebocontrolled trial. Ultrasound Obstet Gynecol. 2007;30(5):687-96.

35. Khan N, Richter KS, Newsome TL, Blake EJ, Yankov VI. Matchedsamples comparison of intramuscular versus vaginal progesterone for luteal phase support after in vitro fertilization and embryo transfer. Fertil Steril. 2009;91(6):2445-50.

36. Veyries ML, Couarraze G, Geiger S, Agnely F, Massias L, Kunzli B, et al. Controlled release of vancomycin from poloxamer 407 gels. Int J Pharm. 1999;192(2):183-93.

37. Hefian E, Elgannoudi E, Mainal A, Yahaya A. Characterization of chitosan in acetic acid: rheological and thermal studies. TurkJ Chem. 2010;34:47-56.

38. Siepmann J, Peppas NA. Hydrophilic matrices for controlled drug delivery: an improved mathematical model to predict the resulting drug release kinetics (the "sequential layer" model). Pharm Res. 2000;17(10):1290-8.

39. Dash AK, Gudworth 2nd GC. Therapeutic applications of implantable drug delivery systems. J Pharmacol Toxicol Methods. 1998;40(1):1-12.

40. Zhang T, Sturgis TF, Youan BB. pH-responsive nanoparticles releasing tenofovir intended for the prevention of HIV transmission. Eur J Pharm Biopharm. 201 1;79(3):526-36.

41. Huang M, Khor E, Lim LY. Uptake and cytotoxicity of chitosan molecules and nanoparticles: effects of molecular weight and degree of deacetylation. Pharm Res. 2004;21(2):344-53.

42. Davidson P, Sofos J, Branen A. Antimicrobials in food. 3rd edn. NW, FL: CRC Press; 2005. 709 p.

43. Costin GE, Raabe HA, Priston R, Evans E, Curren RD. Vaginal irritation models: the current status of available alternative and in vitro tests. Altern Lab Anim ATLA. 2011;39(4): 317-37.

44. Azab AK, Doviner V, Orkin B, Kleinstern J, Srebnik M, Nissan A, et al. Biocompatibility evaluation of crosslinked chitosan hydrogels after subcutaneous and intraperitoneal implantation in the rat. $\mathrm{J}$ Biomed Mater Res A. 2007;83(2):414-22.

45. VandeVord PJ, Matthew HW, DeSilva SP, Mayton L, Wu B, Wooley PH. Evaluation of the biocompatibility of a chitosan scaffold in mice. J Biomed Mater Res. 2002;59(3):585-90. 